\title{
TV and Internet interviews in the structure of media education: transformation of the ontological paradigm
}

\author{
Svetlana Bylkova ${ }^{1, *}$ and Denis Shalkov ${ }^{1}$ \\ ${ }^{1}$ Don State Technical University, 344003, Gagarin sq., 1, Rostov on Don, Russia
}

\begin{abstract}
The purpose of the work: 1) to identify the didactic and educational potential of TV and Internet interviews in the structure of media education; 2) to evaluate the genre-stylistic and language parameters of a modern interview. Methodology. The educational potential of media interviews is revealed with the help of methodological tools of linguistic, social, psychological and pedagogical disciplines. Results. The article proves the need to use TV and Internet interviews as parts of the educational process, since this type of communication allows the consumer of information and media content to receive it literally "firsthand". It is emphasized that the use of interviews in the learning process can become a powerful pedagogical tool. Conclusions/recommendations. When processing the data obtained during the experiment, it turned out that the results of monitoring the social and communicative development of students in two focus groups are characterized by qualitative differences, which are statistically significant. The communicative descriptors of students of the 2 nd focus group that worked with the media content of model native speakers were formed at a higher level, in contrast to the participants of the 2 nd group, who were offered interviews with popular bloggers. JEL Code: I 00, I 20, I 21.
\end{abstract}

\section{Introduction}

In modern science, media education is interpreted as a comprehensive process of developing personal potential based on mass communication, and also includes the interpretation and evaluation of the media text as a form of learning and self-expression. The result of media education is considered to be the formation of media competence, among which the main one is the ability to create and transmit media content in a variety of forms and genre models, including the assessment of its functioning in society. The modern system of higher education cannot be imagined without specialties related to media communications and multimedia technologies (Wolf and Godulla, 2016). The main goal of such faculties is to educate creative media engineers and universal multimedia specialists.

\footnotetext{
*Corresponding author: svetbyl7592@rambler.ru
} 
In a narrow sense, media education is interpreted as an appeal to media texts in the structure of the educational process. The leading genre of media communication is television and Internet interviews. Experts in the field of modern mass media define the interview genre as a special act of communication, which involves communication in the form of a dialogue between the interviewer and the Respondent, in a situation of sequential alternation of questions and answers, where the goal is to obtain information, opinions, and judgments that are of interest to society (Perez and Cremedas, 2014).

Interview as a genre of media communication is characterized by the presence of two or more interlocutors - the interviewer and the interviewees. A modern TV or Internet interview is a hybrid, colloquial-journalistic genre, which determines its style-free, flexible, expressively rich, including elements of colloquial speech and features of popular science style: unprepared, partial or complete spontaneity, irreversibility, the use of rusticated, spoken and slang elements in the conditions of formality. At the same time, an important task of the interview is to ensure accuracy in transmitting the Respondent's information and communication intentions. The interview allows the consumer of information media content to receive it literally "firsthand", hear and see the participants of the interview online (Van Dijck, 2016).

The analysis of the possibilities of new media allows us to say that the interview genre implements two functions in a pragmatic aspect - the message and the creation of speech influence. Some researchers note that the recipient can believe in the rightness of the speaker and accept his opinion in verbal expressions (Kovtunenko et al., 2018). According to O. V. Yeletskaya, the interview is a favorable ground for creating a trusting, relaxed environment, it also allows you to observe the psycho-emotional reactions of the interviewee and monitor the degree of his sincerity. The interpersonal contact between a journalist-interviewer and a Respondent is necessary to fully ensure the implementation of the question-and-answer form of communication as a style feature of any interview (Pincus et al., 2016).

The language realisation of the interview as a genre model is determined by a set of lexical and grammatical (morphological and syntactic) resources. The selection of language tools depends on the communicative goals of the conversation, and is determined by the situation, subject, and situation of the interview. The researchers note that spoken and slang vocabulary in the structure of the statement contributes to the full perception of the text, allowing you to overcome psychological barriers in communication.

The conversational style vector of an interview is created not only by lexical and semantic means, but also by syntactic features of speech: incomplete structure of phrases; repeated questions; numerous pauses in hesitation (unintentional breaks in phonation filled with various sounds that indicate that the fragment of a statement is not yet ready for articulation for one reason or another and therefore additional time is required for its formulation); lexical repetitions; tautological combinations; segmentation of the speech flow and division of a single sentence into several communicatively independent ones; changing the "statement strategy" and, as a result, rearranging phrases in process; using "echo reception" in the question-and-answer complex; the presence of partial constructions and the inversion in the word order.

These structural features are present in almost every TV or Internet interview, regardless of the personality, speech culture, intellectual Outlook, professional qualifications, or socio-political views of the communicators - the interviewer and the Respondent (Ureta, 2011). 


\section{Methodology}

The educational potential of media interviews is revealed using methodological tools of linguistic, social, psychological and pedagogical disciplines, in particular such techniques as observation, description, content analysis, systematization, experimental work in focus groups, as well as elements of statistical, distributive, and structure-function methods of analysis. A hermeneutic approach to the interpretation of the content and language parameters of media content is implemented.

\section{Results}

Interviews with famous philologists, psychologists, and masters of the art have a special didactic and educational potential. Among these people we can name Professor T. V. Chernihiv, one of the leading experts in the field of cognitive Sciences - neuro-linguistics and theory of consciousness; Professor V. I. Annushkina, the Creator of radio and TV programs about the culture of Russian speech, the host of master classes and trainings in public speaking; Professor M. A. Krongauz, a specialist in both applied and theoretical linguistics; a Russian TV host and producer, psychotherapist A.V. Kurpatov - the creator of a new scientific and philosophical direction, called "methodology of thinking" and existing at the interface of neurophysiology, social psychology, cognitive science and modern philosophy of consciousness.

In April 2016, Tatyana Chernigovskaya gave 2 interviews in the popular program of Vladimir Pozner, which was released on channel One. The main topic of conversation was the structure of the human brain. The interviewer touched upon a number of fundamental issues: features of brain functioning; language as a means of thinking, communication and "fighting chaos"; the process of forming mental grammar; the danger of artificial intelligence; the complexity of human language and its differences from other symbolic communication systems; the interaction of the brain and the individual; the superiority of the brain over information and communication technologies.

The interview language organically combines elements of popular science and art styles with the aphoristic nature of journalism. Special terminology used by T. Chernigovskaya ("The fact that your brain is engaged in serious work improves the very quality of neural fibers"; " There are languages where such a sign can be intonation-prosodics so-called...») it is organically intertwined with various colloquial and colloquial elements ("for example, there are stupid parents or stupid teachers"; "... a certain set of phonemes - and we do it with the help of these main semantic, audible, discrete things,"; "At the level of small talk, we understand... »).

Everyday examples used in the Respondent's speech, on the one hand, successfully illustrate complex theoretical calculations, and on the other-due to the recipient of a television interview, which is designed for a mass audience that is not always in the appropriate information field ("screwdriver with a nuclear charge" as a metaphor for experiments with the human genome; comparison of intellectual baggage with a grocery bag or a 220 - kilogram barbell; trained neural structures of the brain-with a LEGO constructor or a set of original atoms, "bricks").

The interviewee's thought is produced by numerous rhetorical questions that mark the logical transition from one microtopic to another: "Genes or education?"; "What should we do about it?"; "What world have we entered?» Metaphorical turns, appeal to the personalities of famous philosophers, scientists, people of culture and art (Aristotle, Platon, I. Kant, A. Schopenhauer, Ch. Darwin, N.P. Bekhterev, N. Homsky, A. Einstein, N. Bohr, V.V. Nabokov, M. Proust, Caravaggio, A. Vivaldi); quoting their statements (S. Kierkegor: "Language is a means of fighting with death»); historical and cultural-esthetic analogies 
give the scientist's speech some journalistic communicative intentions that directly affect the recipient's consciousness (Vobic, 2011): "You enter the classroom, and how can you know who these children are? Among them you can find Mozart or Hitler, maybe Pushkin". Due to the fact that a modern television or Internet interview becomes not only a tool, but also the result of media education, the question about the speech culture of the communicants involved in it arises nowadays. This problem is intertwined with the concept of the language personality of the host and respondent. T. Chernigovskaya's interviews are made primarily for the intellectual viewer (listener, reader) who is interested in the nature of a man and his purpose. Considering language as an interface between the brain, consciousness and the surrounding world, T. Chernihiv translates a scientifically motivated position on the evolution and nature of verbal language and other higher functions, their philo - and ontogenesis, on genetic and cross-cultural aspects of the development of coknowledge and language and their brain correlates, on the possibilities of interspecies communication and modeling of human cognitive processes. Despite the specificity of this issue, it is important to emphasize that $\mathrm{V}$. Posner is on an equal footing with the Respondent: speech culture and the level of education of the interviewer create a productive atmosphere for both polemical discourse and intellectual conversation, which involves information exchange (Strauss and Minker, 2010).

A fundamentally new type of Internet interview has emerged in the modern blogosphere (Halpern Wenger and Owens, 2012). Yuri Dudya's interviews, which are posted in the public domain on the YouTube video hosting service and often gain millions of views, provoke a particular interest among intellectually developed youth audience. The first issue of the Internet show "vDud" appeared on the YouTube channel in early 2017. However, until now, the interviewer's personality causes contradictory assessments: he is accused of being uneducated, shallow, liberal agenda and distortion of facts. In his Internet project, a well-known journalist, TV host and former editor-in-chief of the site Sports.ru interviews musicians, politicians, Internet, culture and film figures, which determines the popular science format of media content and its undoubted educational potential. Interviews with $\mathrm{Yu}$. Dud are built on the model of changing scenes-locations that allow you to move spontaneously from one microtopic of a conversation to another, and then return to the previous one. As a result, the interviewer and his respondents are not bound by the strict limits of the question-and-answer protocol of a traditional interview, which in turn directly affects the speech model of the conversation, which takes on the format of a friendly, relaxed conversation. Konstantin Batygin, a Russian astrophysicist and lecturer at the California Institute of technology, became a guest of one of the vDud program's releases. Outside of the scientific community, he is known primarily as the co-author of the hypothesis of the existence of the ninth planet. The hypothesis was put forward based on the observations of anomalies in the movement of trans-Neptune objects. A few years ago, Forbes magazine included K. Batygina is on the list of 30 scientists under 30 who changed the world. In an interview, the scientist told about how he found himself in the United States, how he combines teaching at the Institute with playing in a rock band and how his astronomical researches are going, as well as about his attitude to the personality and activities of Elon Musk, to the existence of alien civilizations and global environmental problems of our time connected with the myth of the possibility of migration to another planet. As noted by modern researchers, the popularization of scientific postulates and concepts provides a special cognitive space for the media, which often publishes ideas and projects that are not yet fully justified and structured, and potentially can cause (and, in fact, cause) criticism from representatives of the discipline community.

The respondent's language is characterized by numerous unassimilated "foreign language inclusions" (A. A. Leontiev's term) of barbarisms and macaronisms, which is explained by his life and professional activity in the English-speaking environment. At the 
same time, foreign words are spontaneously interspersed with well-constructed Russian speech, implementing the function of mimesis, as well as adaptive and demonstrative interview intentions: "... but I really fell in love with science in my second year, because I met my supervisor at that time, I met him at a party, and we somehow became friends... "; "This is a seismometer" (a special device that is used to detect and register all types of seismic waves); "Almost every day I come to work on longboard" [longboard] (a type of roller boards that are characterized by higher speed, increased stability and improved driving characteristics); "We do this through the so-called exchange..." [exchange]; "When you're with someone for a long time, you go through some iterations... [iterations]" (repeated action); "I am not a stalker [stalker]" (the token is associated with such a concept as "stalking" - obsessive attention to a person or their persecution); "It's okay? [It's OK?]" (Agree?).

It is symptomatic that similar language elements are also found in the speech of the interviewer, realizing the effect of the so-called "language empathy" - the desire to adapt to the Respondent's language manner (Kraft and Seely, 2015): "there Is no just body bag [body bag]?.. "(the expression is used in the battle subculture and means absolute victory; here in the meaning of "irrefutable proof"); " and what kind of geeks [geek] were?» (extremely enthusiastic people; fans; initially, geeks were called people who are passionate about information technology and gadgets).

The analysis of the Russian language of the interview allows to claim that the use of foreign language expressions is not only due to the fact that the respondent cannot find Russian analogues of these lexemes. Transforming into the idioritorics of a scientist, this method of speech construction becomes a specific form of linguistic self-expression of a scientist, his speech "business card" and simultaneously implements a strategy of hedging popular science discourse: language means of certain semantics and metalinguistic operators objectify new scientific knowledge in the form of assumptions, hypotheses that require further proof.

At the same time, special scientific vocabulary that naturally sounds from the lips of a scientist (tripod, interferometer, gravity, hydrodynamics, astrophysics, gravitational signal, electromagnetic waves, parallax, turbulent stratosphere, asteroid orbits, Big Bang theory, string theory, dark matter halo, etc.) regularly alternates with metaphorical comparisons and figurative expressions ("diffusion of culture" as a characteristic of modern society; "surrealism" as an assessment of Japanese cultural traditions; "photo hunting" as a metaphor for astronomical observations), as well as with phrases that mimic the units of the phraseosystem ("When you live in a hole, you need to know what's behind the mountain; when you reach the ocean, what's beyond the ocean?"). Colloquial elements and slang in the framework of the interview under consideration function as separate linguistic inclusions and in some cases perform a phatic (contact-setting) function, as well as contribute to the creation of a special psychological atmosphere of trust, tolerance, openness to dialogue and informality. It is obvious that these communicative intentions are modelled purposefully: on the one hand, to strengthen the interpersonal interaction of communicants; on the other, to provide a more powerful social impact on the audience (Steensen, 2011). That is why in an interview with K. Batygin appears an abundance of slangisms, often perceived as archaic: "Some dude just wrote "NASA" on his van"; "How do people feel about the fact that the Professor goes with iro and still painted?" (iromohawk); "Students do all sorts of jokes to make fun of the professors"; "Japan of the 90's is generally super"; "we have some kind of fun"; "and we thought: "OK, if you count it like that... "; "Who are the coolest Russian scientists in the history of mankind?"; "Or do you buy it in the shop on your own?" "there's an American cosmonaut who was making a speech..."; "So you and your wife binged drink so much that you recollected yourself only on the plane?"; "the whole fan is... ». 
The communicative and pragmatic orientation of the interview determines its drama, which is determined not only by the personality of the interviewee, but also by the specifics of the cultural and speech situation (Tran, 2015). That is why the lexical and syntactic features of TV and Internet interviews are largely determined by the oral form of everyday life and reveal all its most significant typological features (Dowling, Vogan, 2015). The colloquial-slang style vector of an interview is set by certain language parameters, among which the following are most frequent (Jacobson, 2010):

1. An abundance of colloquial and emotional-evaluative vocabulary, including the use of a special conversational style of pronunciation: "Have you seen, I jumped"; "I don't know exactly how much it costs... "; "well, the dog survived... "; "Rock and roll came into my life when I was 12 years old"; "there is no problem that you bring a dog to the office?"; "Michael Brown is the person who shoveled everything we were taught at school... "; "You drive to the observatory... "; "All night you stare at the telescope"; "Is she your fan?"; "You play paintball"; "It's just to keep from dying."

2. The overuse of contact-setting language formulas of spoken nature, which are partially desemanticized lexemes: "Listen, I can't jump"; "And in general, you know, Japan is a great country"; "OK?"; "You know, I met a couple of people at lectures... "; "Look, you and your friend Michael Brown found the 9th planet of the solar system"; "So far this is a hypothesis, right?»

3. The presence of filler words: "But it lasts there like 4 hours"; "I'm, then, sitting, writing formulas"; "On this very, Mauna Kea... This is a mountain on a big island..."; " So the Japanese government pays for it partly..."; "Maybe there are 2 planets there? Could it be like that?"; " How can I say that this is not only in Russia...».

4. High frequency of tautological combinations interpreted as a stylistic marker of spontaneous TV or Internet speech, in which the meaning of the statement often dominates its form: "In Japan, more than in most countries... ».

5. Numerous lexical repetitions as a way to emphasize the content of the statement ("You Know, it's almost always hot here... There are times when the temperature here drops to 10 degrees Celsius. It happens... When this happens, sometimes people panic..."; "It [the seismometer] uses... uses the passage of light through such cables").

6. Repeated infringement of lexical and grammatical norms ("About the Russia of the 90's, from which you left"; "I'm not a Professor of climate science"; " if you imagine on a cosmic scale..."; "In General, when I woke up on a plane...";"Prices here in California are very high").

7. The use of spoken forms of addresses, the use of relics of the vocative case: "Let's try to do it on Seryoga"; " Seryog... ".

8. The aphorism of speech: "There are no real dead ends in science"; "We have something in our DNA that makes us unhappy when we are not looking for something new";" It looks good - I didn't understand anything"; "If you don't do sports, your brain dies".

9. Occasional word formation (using syntactic constructions with verbal nouns that do not exist in the literary language): mathematical proof.

10. Quoting precedent texts of mass culture: "Tell me, American... "(from the iconic movie "Brother-2").

11. The presence of imaginary direct speech, which is traditionally associated with the factors of oral speech and spontaneity (the respondent asks a question and immediately answers himself): "Look, then, will it make our daily life there, will it change our daily life? Of course not."

12. The interviewer's communication with the respondent using "you" (which does not quite correspond to the traditions of Russian linguistic culture), creates a relaxed, trusting atmosphere, the ability to speak in a simple, understandable, everyday language about complex, highly specialized things. 
Using interviews in the learning process can become a powerful pedagogical tool, one of the most effective ways to form cognitive descriptors and meta-skills, as well as general and professional competencies of future specialists. Audio and video recordings of interviews should be regarded as interactive technologies that optimize the methodological support of media education, significantly increasing its quality characteristics and productivity (Hippala, 2017). Especially important the introduction of media interviews in the educational process as a part of the development of specialties 42.03.05 "Media communications" in the profile "Production of digital content" and 09.03.02 "Information systems and technologies" in the profile "Development of media content of applied programs". There is some significant potential for developing intellectual abilities and media competence, which are included in the curricula of these specialties: "Creative writing", "Business rhetoric and the art of presentation", "Culture of oral and written speech", "Literature", "History and theory of media and communications", "Culture of media consumption", "Literary editing of media text" (Karlsson and Clerwall, 2012). In the process of working with students of the faculty "Media Communications and multimedia technologies" of the Don State Technical University, two focus groups with the students of 1st-year (25 students - each) were formed: one of them was offered media content, where professional presenters acted as interviewers; the other group-interview conducted by wellknown bloggers in the Internet space who do not have a special journalistic education (Holling, 2013).

Among the main issues raised in the interviews selected for analysis, the student audience was particularly interested in the problem of forming ideological goals: stages and mechanisms of personal growth, humanistic approach in the process of teaching and upbringing, the ecology of the language, prospects and "pain points" of the development of modern science and technology, futurological concepts, virtual reality as a living environment, the intensification of information and communication technologies, the growing antagonism of spiritual and moral values and pseudo-culture of the era of mass consumption (Jacobson et al., 2015). Students ' project and research activities were carried out in the following areas: transcription of video recordings of interviews and linguistic analysis of their text; interpretation of nonverbal behavior of communicants; writing a reasoned essay on one of the proposed topics; simulation exercises and rhetorical trainings (interactive story-role games-interviews with obligatory change of social roles); organization of discussions aimed at establishing the truth; cognitive classes (object research, construction of concepts, regularities, rules, hypotheses); heuristic conversations to discuss controversial or unresolved issues raised by the interview participants.

The result of the work, which was carried out during one semester, was the diagnosis of social and communicative development of 50 students ( 25 in each focus group) who participated in the experiment, taking into account the following indicators: motivational, value-semantic, emotional-volitional, behavioral, cognitive, communicative-rhetorical and orthological. The descriptors of each of these indicators were evaluated on a 10-point scale, and then summed up and presented as a percentage. Total points and percentages are shown in table 1 .

Table 1. Evaluation of students' social and communicative development of DSTU

\begin{tabular}{|c|c|c|c|c|c|}
\hline \multirow{2}{*}{\multicolumn{2}{|c|}{ Descriptors }} & \multicolumn{4}{|c|}{ Focus groups } \\
\hline & & \multicolumn{2}{|c|}{ Group 1} & \multicolumn{2}{|c|}{ Group 2} \\
\hline & & In points & $\begin{array}{c}\text { As a } \\
\text { percentage }\end{array}$ & $\begin{array}{c}\text { In } \\
\text { points }\end{array}$ & $\begin{array}{c}\text { As a } \\
\text { percentage }\end{array}$ \\
\hline \multirow{3}{*}{$\begin{array}{l}\bar{\pi} \\
0 \\
0 \\
0\end{array}$} & $\begin{array}{l}\text { Interest in collective } \\
\text { communication }\end{array}$ & 210 & 84 & 213 & 85,2 \\
\hline & $\begin{array}{l}\text { Ability to establish friendly } \\
\text { relationships in a team }\end{array}$ & 185 & 74 & 180 & 72 \\
\hline & Ability to maintain social distance & 179 & 71,6 & 170 & 68 \\
\hline
\end{tabular}




\begin{tabular}{|c|l|c|c|c|c|}
\hline & during communication & & & \\
\cline { 2 - 5 } & $\begin{array}{l}\text { Ability to take into account the } \\
\text { personality of the interlocutor }\end{array}$ & 169 & 78,4 & 182 & 72,8 \\
\cline { 2 - 5 } & $\begin{array}{l}\text { Knowledge of collaboration skills } \\
\text { in group activities }\end{array}$ & 200 & 80 & 205 & 82 \\
\hline \multirow{3}{*}{$\begin{array}{l}\text { Ability to formulate the main idea } \\
\text { of media content }\end{array}$} & 212 & 84,8 & 190 & 76 \\
\cline { 2 - 5 } & $\begin{array}{l}\text { Ability to make reasoned, } \\
\text { logically non-contradictory } \\
\text { statements (in oral and written } \\
\text { forms) }\end{array}$ & 165 & 66 & 149 & 59,6 \\
\cline { 2 - 5 } & $\begin{array}{l}\text { Ability to build the composition of } \\
\text { a statement, ensuring sequence } \\
\text { and coherence of the presentation }\end{array}$ & 195 & 78 & 180 & 72 \\
\cline { 2 - 5 } & $\begin{array}{l}\text { Ability to make statements in } \\
\text { accordance with the norms of the } \\
\text { literary language }\end{array}$ & 171 & 68,4 & 155 & 62 \\
\cline { 2 - 6 } & $\begin{array}{l}\text { Ability to formulate correct } \\
\text { questions during a conversation or } \\
\text { discussion }\end{array}$ & 167 & 66,8 & 160 & 64 \\
\hline
\end{tabular}

\section{Conclusions/recommendations}

When processing the data obtained, it turned out that the results of monitoring the social and communicative development of students in 2 focus groups are characterized by qualitative differences that are statistically significant. The communicative descriptors of the students of the 1 st focus group who worked with the media content of model native speakers were formed at a higher level, in contrast to the participants of the 2 nd group, who were offered interviews where popular bloggers in the Internet space acted as presenters. At the same time, the degree of development of social meta-skills among students of both groups does not significantly differ, since it depends not so much on the language content of the media content, but on other extralinguistic factors, including the behavioral models of the interview participants and their drama.

The linguistic characteristics of modern television and Internet interviews indicate that the Russian language's genre and stylistic structure increases the volume of spoken elements due to the merging into a single whole of various layers of the Russian language's vocabulary - elements of journalistic and scientific styles; everyday and spoken vocabulary; slangisms and barbarisms. According to the observations of N.A. Lomova,"activation of the conversational-speech plan" in modern media communication "is primarily associated with the transformation of the existing system of functional-speech styles, which no longer corresponds to the realities of the modern language picture of the world, which is increasingly acquiring the features of the speech picture of the world». In other words, the language of modern mass media discourse is "an open General language sphere that directly correlates both with the literary and normative code, and with the area of socially and territorially marked non-codified (slang) formations", as well as with elements of other speech styles. nterpreting the linguistic features of interviews in the structure of media education, it becomes obvious that the national language consciousness is undergoing a radical transformation of the functional and stylistic hierarchy of the usus (Jacobson, 2012).

Recognizing the undoubted educational potential of television and Internet interviews, it is important to emphasize that in modern Russian speech communication, including in the genres of media communication, a different style usage dominates, characterized by a specific constructive and stylistic vector, which implicates the need to revise not only the concept of the literary norm, but the orthological paradigm as a whole. The described 
language phenomena have a significant impact on the speech culture and social and communicative development of the younger generation, which requires close attention in the selection and implementation of media content in the educational process.

\section{References}

1. D. Dowling, T. Vogan, Can we "Snowfall" this? Digital longform and the race for the tablet market, Digital Journalism, 3(2), 209-224 (2015)

2. D. H. Wenger, L. C. Owens, Help Wanted 2010: An Examination of New Media Skills Required by Top U.S. News Companies, Journalism \& Mass Communication Educator, 67(1), 9-25 (2012)

3. T. Hippala, The multimodality of digital longform, Digital Journalism, 5(4), 420-442 (2017) DOI: http://dx.doi.org/10.1080/21670811.2016.1169197

4. H. B. Holling, Seeking the authentic moment: De- and rematerialisations in Paik's video and multimedia installations, AICCMBulletin, 34(1), 85-92 (2013)

5. S. Jacobson, Emerging Models of Multimedia Journalism: A Content Analysis of Multimedia Packages Published on nytimes.com, Atlantic Journal of Communication, 18, 63-78 (2010)

6. S. Jacobson, Transcoding the news: An investigation into multimedia journalism published on nytimes.com 2000-2008, New Media and Society, 14(5), 86-885 (2012)

7. S. Jacobson, J Marino, R. Gutsche, The digital animation of literary journalism, Journalism, 17(4), 527-546 (2015) DOI: https://doi.org/10.1177/1464884914568079

8. M. Karlsson, C. Clerwall, Patterns and origins in the evolution of multimedia on broadsheet and tabloid news sites, Journalism Studies, 13(4), 550-565 (2012)

9. I. V. Kovtunenko, V. A. Borisenko, S. V. Bylkova, N. A. Minakova, V. I. Rogacheva, Interview as a genre of new media communication: rhetorical relations and pragmatic effects, XLinguae, 11(2), 95-105 (2018) DOI: 10.18355/XL.2018.11.02.08

10. N. Kraft, N. Seely, Making Mojos: How iPads Are Enhancing Mobile Journalism Education, Journalism \& Mass Communication Educator, 70(3), 220-234 (2015)

11. S. Perez, M. Cremedas, The Multimedia Journalist in Large-Market Television Newsrooms: Can Old Dogs Learn New Tricks? Do They Want To?, Electronic News, 8(3), 159-176 (2014)

12. H. Pincus, M. Wojcieszak, H. Boomgarden, Do Multimedia Matter? Cognitive and Affective Effects of Embedded Multimedia Journalism, Journalism and Mass Communication Quarterly, 94(3), 747-771 (2016) doi: 10.1177/1077699016654679

13. S. A. Chunikhin, et al., Studying the banking industry's stability through market concentration indices, Entrepreneurship and Sustainability Issues 6(4), 1663-1679, (2019). doi:10.9770/jesi.2019.6.4(8)

14. P.-M. Strauss, W. Minker, Proactive Spoken Dialogue Interaction in Multi-Party Environments (New York, London, Springer, 2010)

15. H. Tran, More or Less? Multimedia Effects on Perception of News Websites, Electronic News, 9(1), 51-67 (2015)

16. A. L. Ureta, The Potential Of Web-Only Feature Stories. Journalism Studies, 12(2), 188-204 (2011)

17. J. Van Dijck, Picturizing science: the science documentary as a multimedia spectacle, International Journal of Cultural Studies, 9(1), 5-24 (2016) 
18. I. Vobic, Online multimedia news in print media: A lack of vision in Slovenia, Journalism, 12(8), 946-962 (2011)

19. C. Wolf, A. Godulla, Potentials of digital longforms in journalism. A survey among mobile Internet users about the relevance of online devices, Internet-specific qualities, and modes of payment, Journal of Media Business Studies, 13(4), 199-221 (2016) DOI: $10.1080 / 16522354.2016 .1184922$ 